\title{
Forum
}

\section{An Optimal Estimating Method for Celestial Navigation}

\author{
Wu Guanghua \\ (Jimei Navigation Institute, People's Republic of China)
}

\begin{abstract}
In celestial navigation, the altitude difference between a sextant reading and the prediction of the reading derived from the GMT and the dead reckoning position (DR) multiplied by factors $\mathrm{K}_{1}$ and $\mathrm{K}_{2}$ can generate the position difference between the DR and the optimal estimated position, even if with only a single observation.

$\mathrm{K}_{1}$ and $\mathrm{K}_{2}$ come from a nonlinear Kalman filter. A computer accomplishes all the computing work and displays the best estimate of position in real time.

Computer simulation and experiment at sea indicate that positioning accuracy is very good; the 2 drms is 3.93 nautical miles. Usually, near noon the positioning error is within 1 nautical mile.
\end{abstract}

I. INTRODUCTION. In celestial positioning, constructing a line of position (LOP) from an azimuth and an altitude difference to find a ship's position has been a global navigation method since 1875 . Celestial navigation was the only method for ocean-going ship navigation before the Omega and satellite systems were available. However, the method is inconvenient and complex and it is easy to make mistakes.

Many radionavigation systems such as Loran, Omega, NNSs and GPS, have been developed to improve the navigation situation, but low-cost, reliable celestial navigation is still of interest, especially when a computer is used.

Many people have presented research results including equipment and methods over the years, and a particularly interesting one is the Least Square Method. This method is very robust and it needs little statistical information, but it does need more observations and considerable waiting time which make it difficult to get a ship's position in real time. ${ }^{1,2}$

This paper presents an optimal estimating method which makes celestial navigation more accurate, convenient, easy and reliable.

2. Position OPtimal estimating. Fig. I shows an outline of the positioning method.

The engine, rudder, current, wind and wave etc. act on the ship as it sails on its track. The navigator who observes a celestial body at TG (GMT) measures Hs (the sextant reading) which includes the observing noise, $V$.

The computer calculates the ship dead reckoning position (DR), LATc and LONGc, corresponding to the GMT, Course, Speed, Drift, Set, etc. and computes the Greenwich Hour Angle (GHA) and the declination corresponding to the GMT as well as computing the predicted value of the sextant reading, Hsp.

The altitude difference, $\mathrm{DH}$, which is obtained from $\mathrm{Hs}$ - Hsp multiplied by factors $K_{1}$ and $K_{2}$, generates the position differences Dlat. and Dlong, where $K_{1}$ and $K_{2}$ come from a nonlinear Kalman filtering gain matrix. 


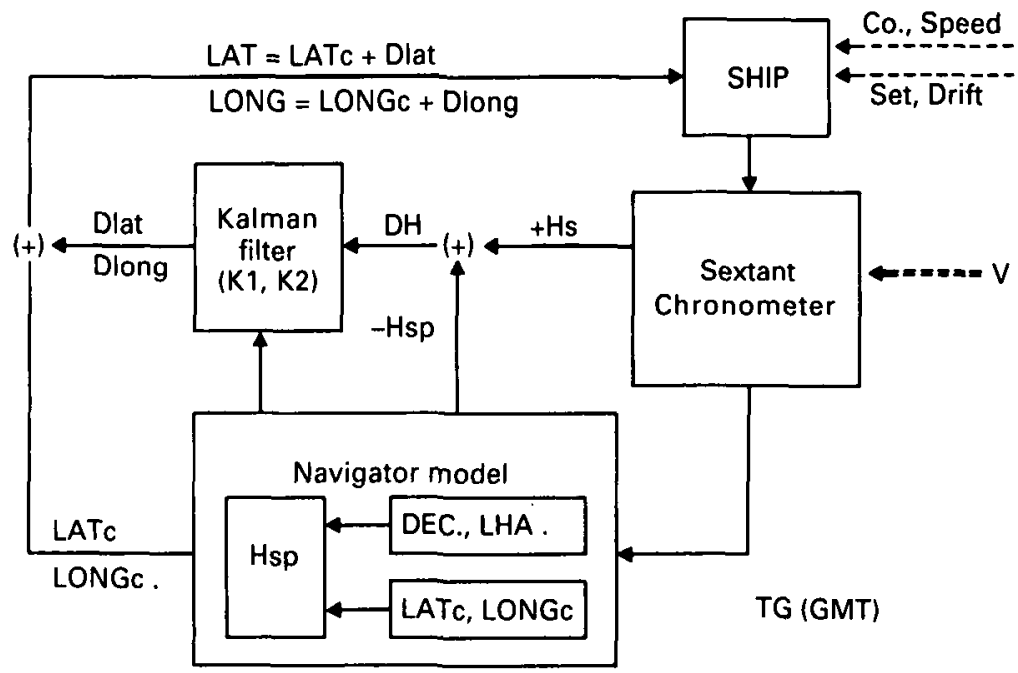

Fig. 1. Outline of the celestial position method

The best estimate of ship position can then be obtained from equation (1).

$$
\left.\begin{array}{l}
\text { LAT }=\text { LATc }+ \text { Dlat. } \\
\text { LONG. }=\text { LONGC + Dlong. }
\end{array}\right\}
$$

3. POSITIONING ACCURACY. Computer simulation and experiment at sea indicate that positioning accuracy is very good; the 2 drms is 3.93 nautical miles, even when sailing in the centre of a $984 \mathrm{mb}$ low pressure.

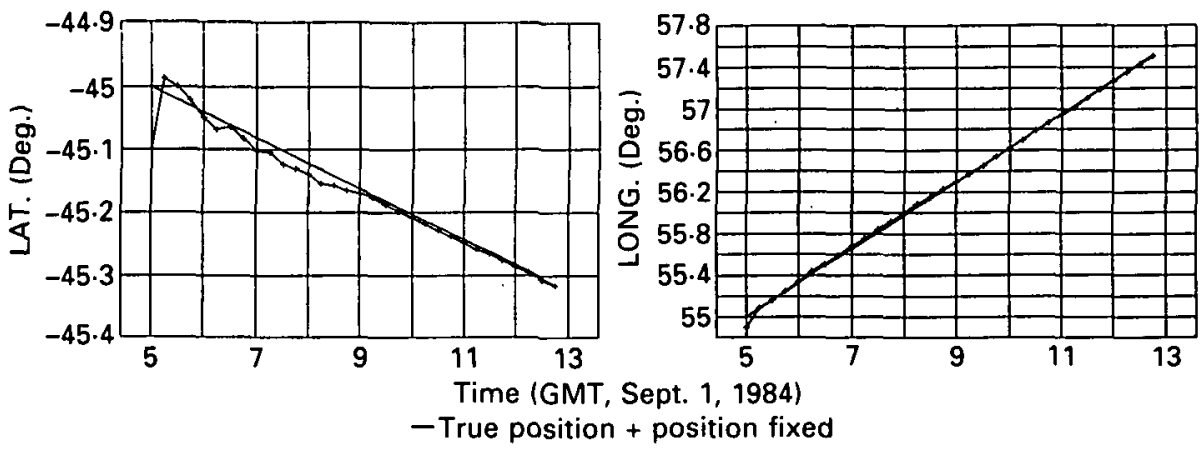

Fig. 2. Simulation result

We have simulated observations north and south of the equator in the Pacific, Atlantic and Indian oceans, in 6 areas. Fig. 2 shows one of the results.

On Sept. I 1984 a ship was sailing in the South Indian Ocean.

Start Time GMT : 0500 $\mathrm{ZT}:+4$ (time zone)

True position: Lat. $45.0^{\circ} \mathrm{S}$. Long. $55^{\circ} 0^{\circ} \mathrm{E}$.

DR position: Lat. $45^{\circ} 1^{\circ} \mathrm{S}$. Long. $54.9^{\circ} \mathrm{E}$.

Co. $100^{\circ}$

Speed : 14 knots

error of $\mathrm{Hs}<3^{\prime}$

Height of eye : $25 \mathrm{~m}$ 


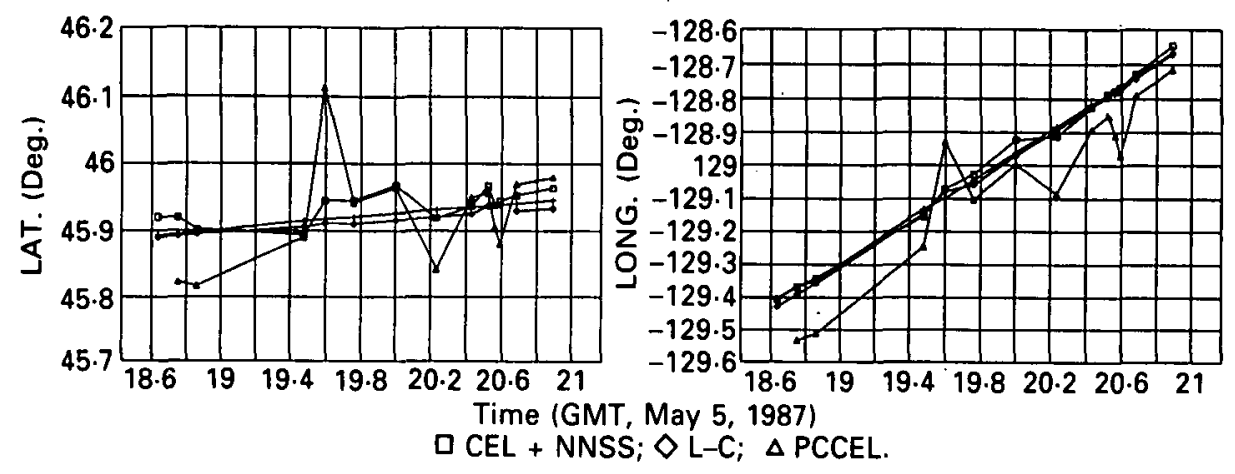

Fig. 3. Experiment at sea

The simulation result indicates that positional accuracy is very good, most of the errors being very small (within $\mathbf{I}^{\prime}$ ).

The optimal estimating method has also been applied to the HX- 1113 Astronomical Navigator which was installed on the bridge of the Jian Feng Ling, a ship which belongs to the GuangZhou Marine Transportation Bureau. All the officers and the captain of the ship took part in an experiment in the North Pacific Ocean in 1987. Fig. 3 shows us a result from the trials.

Date of the experiment: May 5, 1987

Time: 174019 (GMT)

DR : Lat. $45^{\circ} 52.54^{\prime} \mathrm{N}$

094000 (ship time)

Co. : $085^{\circ}$

Long. $129^{\circ} 43^{\circ} 60^{\prime} \mathrm{W}$

Speed : 13 knots

Set : $077^{\circ}$

I $+1 \mathrm{IC}: \mathbf{2}^{\prime} \cdot 7$

Drift: 0.9 knots

Height of eye : $20 \mathrm{~m}$

Ist time of positioning: 183816 (GMT) Last time : 205333 (GMT)

Fig. 4 illustrates the results of another test in April, 1987.

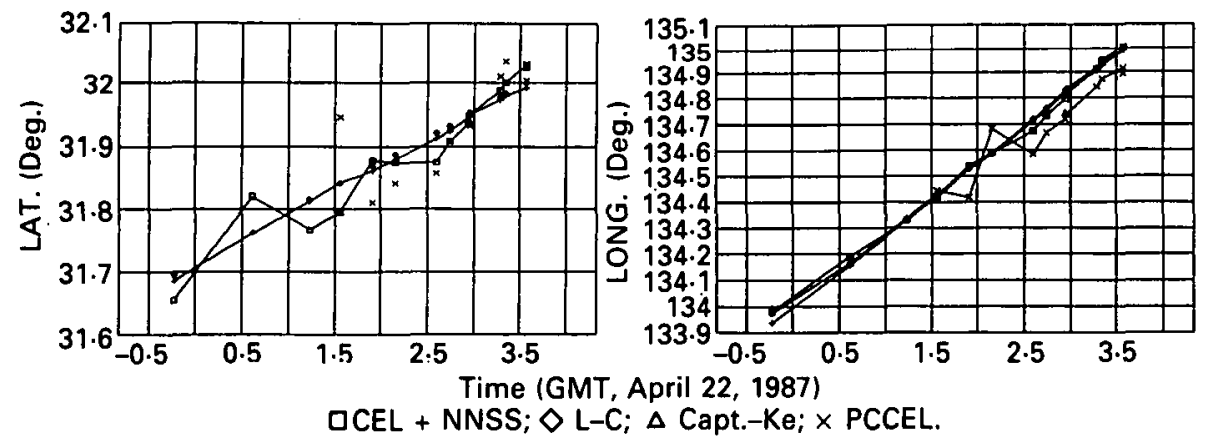

Fig. 4. Experiment at sea

Fig. 3 and Fig. 4 illustrate the comparative positioning results using NNSs, Loran-C and the Sun. The Sun observations include the optimal estimating method with ' $\mathrm{HX}$ I I 13 ', marked CEL, and the traditional method with 'PC ASTRO NAVIGATOR', marked PCCEL and plotted by Captain Ke. They indicate that the optimal estimating method can 
be used for celestial navigation and that the positioning accuracy with it is good. In fact, we have obtained similar results in all other tests. ${ }^{2,3}$

4. CONCLUSION. The optimal estimating method described in this paper could make accurate celestial positioning possible in real time. If it is applied to a sextant which can obtain GMT and an altitude reading by pushing one or two buttons, a navigator who requires his position need only push the buttons when he observes the height of a celestial body and he will be able to get his position in a few seconds. In this way, celestial navigation will be more convenient, accurate, easy and reliable.

\section{R E FER E N C ES}

1 Dalian Marine College (1984). Least Square Method for Celestial position. Internal report, Oct.

${ }^{2}$ Wu Guanghua (1988). A new astronomical navigation aid. Journal of the Jimei Navigation Institute.

3 Wu Guanghua (1989). Modern astronomical navigation. Jimei Navigation Institute report, Oct.

${ }^{4}$ Severance, R. W. ( $\left.1989-90\right)$. Overdetermined celestial fix by iteration. Navigation, Journal of the U.S. Institute of Navigation, Vol. 36, No. 4.

1. Astro. 2. Computers.

\section{The Cocked Hat}

\section{J. E. D. Williams}

There is a BBC Open University statistics programme devoted to the 'Cocked Hat', which is long on legerdemain and shots of ladies with bearing compasses in a little boat,

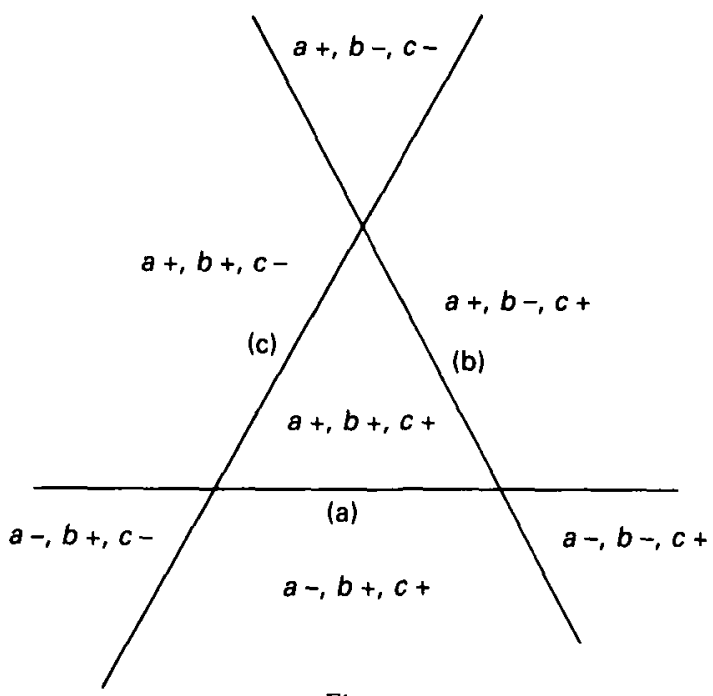

Fig. 1 